\title{
OBTURATOR PALSY IN THE NEWLY BORN
}

\author{
BY \\ W. S. CRAIG and J. M. P. CLARK \\ From the Department of Paediatrics and Child Health, and the Department of Orthopaedics, \\ The University of Leeds
}

(RECEIVED FOR PUBLICATION JULY 20, 1962)

Peripheral nerve palsies affecting a limb or limbs in the newly born are uncommon. The experience of the authors in a maternity teaching hospital suggests that the incidence is approximately 1 to 2 per 1,000 live births. Involvement of the lower limbs is especially uncommon (von Reuss, 1920; Brennemann, 1960) and paralysis of the obturator nerve is extremely rare. Two examples are described in this paper. In a previous discussion of the first case the authors (Craig and Clark, 1958) suggested that the palsy was attributable to mechanical factors operating in utero. Findings in the second case afford further evidence in support of the theory.

\section{Case Reports}

Case 1. A baby girl born on June 15, 1957, birth weight $7 \mathrm{lb} .3 \mathrm{oz}$. (3,260 g.); estimated gestation period 40 weeks; presentation, breech; delivery by caesarean section on account of maternal toxaemia. The mother was 32 years of age; it was her first pregnancy.

The baby's general condition was satisfactory at birth and there was no delay in the establishment of rhythmic respirations. Immediately after delivery the right lower limb was in a position of full external rotation and abduction at the hip, the knee being flexed. Examined at the age of 18 hours the limb could be abducted to 90 degrees, and during passive flexion of the right hip and knee, adductor resistance was absent and the thigh and leg assumed a position of external rotation. Active internal rotation and adduction of the thigh were markedly impaired and active extension of the knee moderately limited (Fig. 1). No impairment of sensation was detectable and there was no bruising or abrasions of the affected limb. The right leg gradually assumed a normal position and normal adductor and internal rotator function became established. Complete disappearance of the palsy took place over a period of 10 to 14 days. No splintage was used.

Case 2. A baby girl, born on May 28, 1962, birth weight $4 \mathrm{lb} .15 \mathrm{oz}$. (2,240 g.); estimated gestation period was 40 weeks; presentation, vertex L.O.A.; delivery was instrumental on account of irregular, slowing foetal heart and inability of the mother to bear down effectively during the second stage. The mother was 27 years of age. Her only previous pregnancy was a therapeutic abortion in 1957. The mother was paralysed in both lower limbs having been diagnosed as suffering from multiple sclerosis at the age of 15 years. She had declined sterilization.

At birth the infant's general condition was characterized by features of foetal malnutrition including dryness of the skin, sparsity of subcutaneous fat, gaunt facies, hard cranial bones and flat abdominal contour. There were multiple infarctions of the placenta. Regular rhythmic respirations were established within two minutes. During delivery it was noted that the position of the left lower limb was unusual. There was full flexion and a moderate degree of abduction and external rotation at the hip, and partial flexion of the knee joint. The medial aspect of the thigh lay in contact with the left side of the chest, the knee being situated in close proximity to the axilla, and the foot being the first part of the limb seen during delivery of the baby. Examined at the age of 1 hour the left thigh and leg had adopted a position of external rotation, and adductor resistance was found to be absent during passive flexion of the left hip and knee. The affected limb could be abducted at the hip without difficulty to 90 degrees. There was pronounced limitation of active internal rotation and adduction of the thigh and of

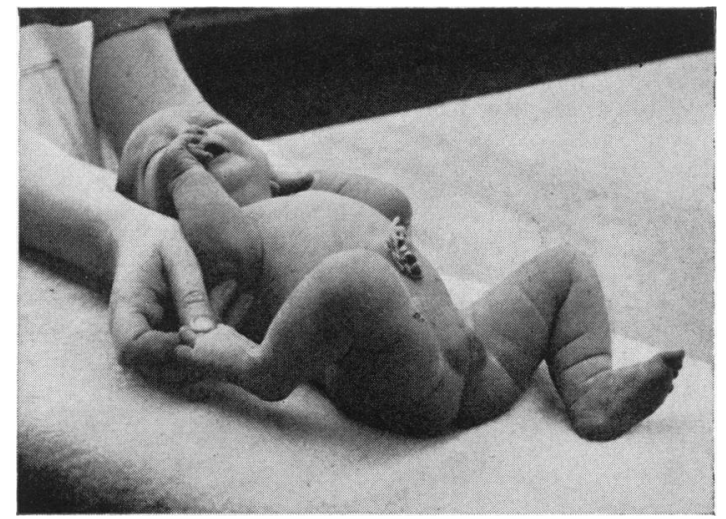

FIG. 1.-Case 1: right obturator nerve palsy. 


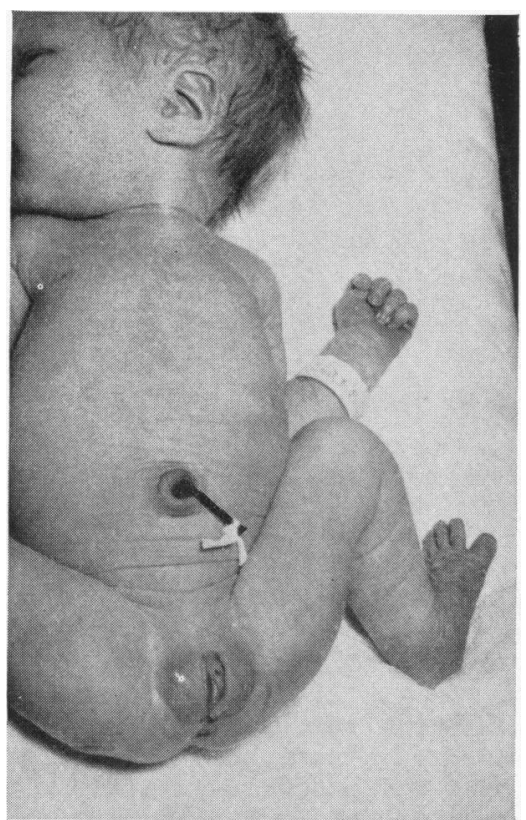

FIG. 2.-Case 2: left obturator nerve palsy.

active and passive extension of the knee (Fig. 2). Impairment of sensation was not detected, and there were no bruises or abrasions of the limb. Return of adductor and internal rotator function was spontaneous but gradual, all evidence of nerve palsy finally disappearing completely within 14 to 16 days. Splints were not applied.

\section{Discussion}

The findings in both babies were diagnostic of obturator nerve palsy. A feature common to both infants was the position at the time of birth of extreme flexion, external rotation and abduction at the hip, together with flexion at the knee of the affected limb. In neither case could the position of the limb be attributed to difficulties of, or manipulations during delivery, and in neither case was there evidence of superficial trauma to suggest that the infant had been subjected to abnormal external pressure during delivery. All the evidence favours the view that the position of extension, abduction and external rotation at the hip in the affected limbs had been present for a considerable time in utero.

As discussed elsewhere (Craig and Clark, 1958) prolonged abduction at the hip involves sustained traction of the obturator nerve between points of fixation at the knee joint and the pubic ramus. Sustained traction first gives rise to neural ischaemia which in turn gives rise to neurapraxia. The spontaneous complete recovery of the obturator palsy in the two cases was in keeping with a diagnosis of neurapraxia.

\section{Summary}

Two cases of obturator nerve palsy are described. In each case the palsy is considered to be an example of neurapraxia caused by sustained traction on the nerve consequent upon the intrauterine position of the limb.

Fig. 1 was taken by Dr. M. F. Buchanan, and is reproduced by courtesy of the Editor of the Journal of Obstetrics and Gynaecology of the British Commonwealth. Mr. A. L. Pegg, A.R.P.S., of the University Department of Medical Photography was responsible for Fig. 2. Access to the babies was by courtesy of our obstetrical colleagues, Mr. D. W. Currie and Mr. J. B. Farquhar.

\section{REFERENCES}

Brennemann, J. (1960). Practice of Pediatrics, Vol. 1, chap. 42, p. 70 Prior, Hagerstown, Maryland.

Craig, W.'S. and Clark, J. M. P. (1958). Of peripheral nerve palsies in the newly born. J. Obstet. Gynaec. Brit. Emp., 65, 229.

von Reuss, A. R. (1920). The Diseases of the Newborn, p. 189. Bale, Sons and Danielsson, London. 